\title{
Predictors of Overweight and Obesity among Children in Haldwani, Uttarakhand
}

\author{
Bhawna Choudhary ${ }^{\circledR 1}$, Nutan Singh ${ }^{\circledR 2}$, Ankush Bathla ${ }^{\oplus 1}$, Ramesh Chand ${ }^{\circledR 3}$ \\ ${ }^{1}$ Post Graduate Resident, Department of Pediatrics, Government Medical College, Haldwani, Nainital, Uttarakhand, India, ${ }^{2}$ Associate Professor, Department of \\ Pediatrics, Government Medical College, Haldwani, Nainital, Uttarakhand, India, ${ }^{3}$ Assistant Professor, Department of Pediatrics, Government Medical College, \\ Haldwani, Nainital, Uttarakhand, India.
}

\section{Abstract}

Background: Obesity has become a concerning pediatric health problem in the modern era with lifestyle changes in globalization, economic development and easy access to technology. The aim of the study is to study the anthropometric profile of overweight and obesity and its associated risk factors. Subjects and Methods: A school-based cross-sectional study was implemented among randomly chosen 100 obese and overweight children aged between 10-18 years over 15 months. Data was collected using a structured self-administered questionnaire and anthropometry was done and categorized as overweight and obese as per WHO BMI- age cutoff. Results: $41 \%$ ( $\mathrm{n}=41$ ) were obese and $59 \%$ $(n=59)$ were overweight. $65 \%(n=65)$ were males. In all the age groups the mean weight of males was more except in the age group 10-12 years. Mean weight $(64.39 \pm 12.88 \mathrm{~kg})$ and mean BMI $(26.04 \pm 1.95 \mathrm{~kg} / \mathrm{m} 2)$ of obese children is significantly higher than mean weight $(56.73 \pm 9.76$ $\mathrm{kg})$ and mean BMI $(23.25 \pm 1.98 \mathrm{~kg} / \mathrm{m} 2)$ of overweight children respectively. Risk factors like skipping breakfast ( $\mathrm{p}=0.034)$, calorie excess $(\mathrm{p}=0.032)$, junk food intake more than once $(\mathrm{p}=0.008)$ and junk food daily $(\mathrm{p}=0.036)$ were found to be significantly associated with childhood obesity. Conclusion: Sensitization of parents and teachers with school-based programs like active participation in sports, regular anthropometric examinations of students are important measures that can be taken to curb this rising problem.

Keywords: Childhood Obesity, School-Aged Children, Unhealthy Diet

Corresponding Author: Nutan Singh, Associate Professor, Department of Pediatrics, Government Medical College, Haldwani, Nainital, Uttarakhand, India.

E-mail: drnutansingh_stm@yahoo.com

Received: 17 March 2020

Revised: 19 April 2020

Accepted: 2 May 2020

Published: 5 July 2020

\section{Introduction}

Obesity is considered one of the most serious health challenges of the $21^{\text {st }}$ century. Obesity is an important pediatric public health problem associated with the risk of complications in childhood and increases mortality and morbidity throughout adult life. ${ }^{[1]}$

Overweight and obesity are the fifth leading risk of global deaths. ${ }^{[2]}$ Over 340 million children and adolescents aged 519 years were overweight or obese in 2016 and prevalence has risen dramatically from $4 \%$ in 1975 to $18 \%$ in $2016 .{ }^{[3]}$ Developing countries like India have a unique problem of double burden wherein at one end we have obesity in children and at the other end we have malnutrition and underweight. With the increased adaptation of western lifestyle and food habits and childhood obesity has now attained alarming proportions in India. A systematic review in 2016 estimated combined prevalence of 19.3 percent of childhood overweight and obesity in India. ${ }^{[4]}$ Kumar and Sharma (2013) stated the overall prevalence of overweight and obesity to be 14 and $18 \%$ in Uttarakhand. ${ }^{[5]}$

Obesity is defined as an accumulation of excess body fat, to such an extent that health might be impaired. ${ }^{[1]}$ Etiologies of childhood overweight and obesity include modifiable and non-modifiable risk factors. Modifiable risk factors include unhealthy eating habits, physical inactivity, sedentary lifestyle, socioeconomic status, media usage, and inadequate play area, family factors, psychological factors, and social factors, sleep alteration while non-modifiable risk factors include genetics, neuroendocrine factors and drugs.

Through this study, we aimed to identify the anthropometric profile of overweight and obese children and risk factors associated with childhood obesity. 


\section{Subjects and Methods}

This cross-sectional study was conducted on randomly selected children of age group of 10 to 18 years from the school visits in a city in Uttarakhand who fit in inclusion criteria between a period of January 2018 to April 2019 whose body mass indices are above 85 th percentile or $>2 \mathrm{SD}$ according to WHO cutoff for age and sex included in the study. Children $<10 \mathrm{yrs}$ or $>18 \mathrm{yrs}$, children who are mentally challenged and children with any other chronic illness or pathology causing obesity were excluded from the study.

For children and adolescents, overweight and obesity are usually defined using age and gender-specific nomograms of BMI. A total of 100 overweight/obese children according to the WHO growth chart for age and gender were enrolled in the study. Written informed consent was obtained from their parents before the commencement of the study. The study was approved by the Institutional Ethics Committee.

Study proforma included basic information of the subjects and family members, detailed history of dietary habits and family history of obesity (based on BMI of either parents/sibling). Clinical examination of all children was performed by pediatricians to assess their health status and anthropometric parameters were measured.

Daily food intakes were evaluated through a structured selfadministering questionnaire. Physical activity was ascertained by asking time spent for daily physical activity or in sports activities (yoga, walking, cycling, jogging, swimming, dancing, school sports/games and playing outdoor games) was considered as a moderate activity for at least 60 minutes/day for 3 days during the past 7 days. Routine activity patterns like walking to school or mode of conveyance used. Sedentary behavior including the hours spent watching television, mobile phones, video games, computer/laptop usage, to determine whether screen time is $>2$ hours per day.

Anthropometric measurements including weight, height and BMI were recorded.

\section{Anthropometry}

1. Weight - Body weight was measured with an electronic digital scale with subject lightly dressed and without shoes.

2. Height - Height was measured to the nearest $0.1 \mathrm{~cm}$ with metallic nonstretchable tape with subject lightly dressed and without shoes taking into account that heels, buttocks, shoulders and head are closed to a vertical wall surface.

3. Body mass index (BMI) - was calculated by the standard formula: Weight in $\mathrm{kg} /$ (height in meters)2. As per WHO growth curves, children were classified as overweight if BMI $>$ 85th to 95th percentile and as obese if BMI is $>95$ th percentile.

\section{Statistical analysis}

Data was recorded on a predesigned proforma and managed on an EXCEL spreadsheet. Qualitative variables were correlated using the Chi-Square test. Quantitative variables were compared using the Un-paired t-test between the two groups and the ANOVA test was used for comparison between more than two groups. A p-value of less than 0.05 was considered statistically significant. Data analysis was done using Statistical Package for Social Sciences (SPSS) version 21.0.

\section{Results}

A total of 100 subjects were enrolled in the study. In this study we found $59 \%(\mathrm{n}=59)$ were overweight and $41 \%$ $(n=41)$ were obese. $65 \%(n=65)$ males were overweight and obese, while $35 \%(n=35)$ females were overweight and obese. [Table 1] showing significant association $(\mathrm{p}<0.05)$ showing predominance of obesity in the male sex.

Mean weight is more in females in the age group 10 to $12 \mathrm{yrs}$ as compared to males, while in the other two age groups (1315 and 16-18) mean weight is more in males as summarized in [Table 2].

Among risk factors, family history of obesity, skipping breakfast, junk food and excess calories were found to be significantly associated with overweight and obesity $(p<0.05)$ as shown in [Table 4].

\section{Discussion}

Obesity, an important health problem, has definitely increased in prevalence in the past few decades throughout the world both in developed as well as developing countries.

This study was done on 100 subjects among which $59 \%(n=59)$ were overweight and $41 \%(\mathrm{n}=41)$ were obese subjects similar to a study done by Kotian et al. in South India and Patil LGC et al in Karnataka 2018. ${ }^{[6,7]}$ Obesity was predominant in male than female children $(65 \%, \mathrm{n}=65$ vs. $35 \%, \mathrm{n}=35)$. Similar results were shown in a study done by Verma et al. in West Delhi. ${ }^{[8]}$ Out of 65 male subjects, obese children were almost equal $50.77 \%(\mathrm{n}=33)$ as overweight children $49.33 \%(\mathrm{n}=32)$ while among 35 female subjects, mostly $(77.14 \%, \mathrm{n}=27)$ were overweight in contrast to study by Jagadesan et al in Chennai showing a higher percentage of overweight and obesity both in female while other studies by Shah et al. In Mehsana district, Gujarat showing predominance of both overweight and obesity in males. ${ }^{[9,10]}$

In all age groups, overweight and obese children were more in male than female. Similar results were shown in a study done by Verma et al. in West Delhi. ${ }^{[8]}$ There was a significant difference in mean weight and BMI among overweight and obese children. 


\begin{tabular}{lllllll}
\hline \multicolumn{7}{l}{ Table 1: Overweight and obesity among male and female } \\
\hline Body mass index & Sex & \multicolumn{7}{l}{} & Total & p valueq \\
& Male & & Female & & \\
\hline & N & \% & N & \% & N (\%) & $0.007^{*}$ \\
Overweight & 32 & 49.23 & 27 & 77.14 & $59(59 \%)$ & \\
Obese & 33 & 50.77 & 8 & 22.86 & $41(41 \%)$ & \\
Total & 65 & 100 & 35 & 100 & 100 & \\
\hline
\end{tabular}

Chi-square test, $*$ Significant

Table 2: Age group wise comparison of mean weight among males and females

\begin{tabular}{|c|c|c|c|c|c|}
\hline Age (in years) & Male & $\begin{array}{l}\text { Weight (in } \\
\text { MEAN } \pm \text { SD }\end{array}$ & Female & $\begin{array}{l}\text { Weight (in } \quad \text { Kg) } \\
\text { Mean } \pm \text { SD }\end{array}$ & p-valueq \\
\hline $10-12$ & 20 & $48.4 \pm 7.68$ & 14 & $49.79 \pm 6.6$ & $<0.001^{*}$ \\
\hline $13-15$ & 29 & $62.52 \pm 10.28$ & 11 & $61 \pm 3.92$ & \\
\hline $16-18$ & 16 & $75.31 \pm 5.46$ & 10 & $63.3 \pm 3.8$ & \\
\hline TOTAL $(\mathrm{n}=100)$ & 65 & & 35 & & \\
\hline
\end{tabular}

Anova test, *Significant

Table 3: Anthropometric profile of overweight and obese subjects

\begin{tabular}{lccc} 
& Overweight $\mathbf{n}=\mathbf{5 9}$ & Obese $\mathbf{n}=\mathbf{4 1}$ & p-value \\
Body Mass Index (in $\left.\mathrm{kg} / \mathrm{m}^{2}\right)$ & & & $<.0001^{*}$ \\
Mean \pm SD & $23.25 \pm 1.98$ & $26.04 \pm 1.95$ & $0.001^{*}$ \\
Weight (in kg) & $56.73 \pm 9.76$ & $64.39 \pm 12.88$ & \\
Mean \pm SD & & & \\
\hline
\end{tabular}

unpaired t-test, *significant

We found a positive association between BMI and family history of obesity. Our observations were similar to previous studies done by Nageshwar Rao et al and Musaiger et al. ${ }^{[1,12]}$

We found more risk of overweight and obesity in breakfast skippers in comparison to children who take breakfast regularly. Our finding is similar to several other studies. ${ }^{[13,14]}$ Regarding dietary patterns, our study showed a significant association of consumption of junk food of more than once in a week and the risk of obesity. A similar finding was also reported by Goyal RK et al. and Kaushik, J.S. et al. ${ }^{[15,16]}$

Children with an intake of high-calorie foods preponderated towards the risk of overweight and obesity. This finding was similar with a previous study done by Goyal RK et al. and Subhash et al. ${ }^{[15,17]}$ The intake of calories more than our body requirement leads to positive energy balance and so obesity.

\section{Conclusion}

It can be concluded from our study that genetics was found to be an important cause of obesity as the chance of being obese increases if parents are obese. Unhealthy dietary practices like eating junk foods and excess calorie consumption and skipping breakfast were found to be significantly associated with obesity.

\section{References}

1. Karnik S, Kanekar A. Childhood Obesity: A Global Public Health Crisis. Int J Prev Med. 2012;3(1):3-7.

2. Garg A, Anand T, Sharma U, Kishore J, Chakraborty M, Ray PC, et al. Prevalence of Risk Factors for Chronic Non-communicable Diseases Using WHO Steps Approach in an Adult Population in Delhi. J Family Med Prim Care. 2014;3(2):112-118. Available from: https://dx.doi.org/10. 4103/2249-4863.137617.

3. Prevalence of Childhood Obesity in an Affluent School in Telangana Using the Recent IAP Growth Chart: A Pilot Study. Indian J Endocrinol Metab. 2019;23(4):428-432. Available from: https://dx.doi.org/10.4103/ijem.IJEM_151_19.

4. Mohan V, Ranjani H, Mehreen TS, Pradeepa R, Anjana R, Garg R, et al. Epidemiology of childhood overweight \& obesity in India: A systematic review. Indian J Med Res. 2016;143(2):160-165. Available from: https://dx.doi.org/10. 4103/0971-5916.180203. 


\begin{tabular}{|c|c|c|c|c|c|}
\hline Risk Factors & & $\begin{array}{l}\begin{array}{l}\text { Overweight } \\
(\mathrm{n}=59)\end{array} \\
\text { No.(\%) }\end{array}$ & $\begin{array}{ll}\text { Obese } & (n=41) \\
\text { No. }(\%) & \end{array}$ & Total & p-value \\
\hline \multirow[t]{2}{*}{ Family History Of } & Yes & $12(20.34 \%)$ & $16(39.02 \%)$ & 28 & $0.043 *$ \\
\hline & No & $47(79.66 \%)$ & $25(60.98 \%)$ & 72 & \\
\hline \multirow[t]{2}{*}{ Physical Activity } & Yes & $15(25.42 \%)$ & $8(19.51 \%)$ & 23 & 0.491 \\
\hline & No & $44(74.58 \%)$ & $33(80.49 \%)$ & 77 & \\
\hline \multirow[t]{2}{*}{ Breakfast Skipping } & No & $39(66.10 \%)$ & $36(87.81 \%)$ & 75 & $0.014 *$ \\
\hline & Yes & $20(33.90 \%)$ & $5(12.19 \%)$ & 25 & \\
\hline \multirow[t]{3}{*}{ Junk Food } & Daily & $1(1.70 \%)$ & $4(9.75 \%)$ & 5 & $0.002 *$ \\
\hline & $\begin{array}{l}\text { More than one day } \\
\text { /week }\end{array}$ & $39(66.10 \%)$ & $35(85.37 \%)$ & 74 & \\
\hline & One day /week & $19(32.20 \%)$ & $2(4.88 \%)$ & 21 & \\
\hline \multirow[t]{2}{*}{ Use Of Media } & $>2$ hours & $56(94.92 \%)$ & $35(85.37 \%)$ & 91 & $0.155^{*}$ \\
\hline & $<2$ hours & $3(5.08 \%)$ & $6(14.63 \%)$ & 9 & \\
\hline \multirow[t]{3}{*}{ Transport for school } & Cycle & $4(6.78 \%)$ & $6(14.63 \%)$ & 10 & 0.226 \\
\hline & Motor vehicle & $50(84.75 \%)$ & $34(82.93 \%)$ & 84 & \\
\hline & Walk & $5(8.47 \%)$ & $1(2.44 \%)$ & 6 & \\
\hline \multirow[t]{2}{*}{ Mother Occupation } & Housewife & $50(84.75 \%)$ & $32(78.05 \%)$ & 82 & 0.393 \\
\hline & Working & $9(15.25 \%)$ & $9(21.95 \%)$ & 18 & \\
\hline \multirow[t]{3}{*}{ Sleep Hours } & $<7$ hours & $2(3.39 \%)$ & $2(4.88 \%)$ & 4 & 0.743 \\
\hline & 7- 9 hours & $52(88.14 \%)$ & $37(90.24 \%)$ & 89 & \\
\hline & $>9$ hours & $5(8.47 \%)$ & $2(4.88 \%)$ & 7 & \\
\hline \multirow[t]{2}{*}{ Excess Calories } & Yes & $31(52.54 \%)$ & $31(75.61 \%)$ & 62 & $0.019 *$ \\
\hline & No & $28(47.46 \%)$ & $10(24.39 \%)$ & 38 & \\
\hline
\end{tabular}

*significant

5. Kumar R, Sharma SK. Trends of communicable and noncommunicable morbidities in Uttarakhand state: a systemic review. Indian J Community Health. 2013;25(2):178-187.

6. Kumar SG, Kotian SS, Kotian MS. Prevalence and determinants of overweight and obesity among adolescent school children of South Karnataka, India. Indian J Comm Med. 2010;35(1):176-180. Available from: https://dx.doi.org/10. 4103/0970-0218.62587.

7. Patil LGC, S S. Comparison of clinical and biochemical profile of obese and nonobese children. Int J Contemp Pediatr. 2018;6(1):185-185. Available from: https://dx.doi.org/10. 18203/2349-3291.ijcp20185206.

8. Bagri DR, Verma V, Sharma VK, Barouha R, Haque FA. Predictors of prevalence of overweight and obesity in children. Int J Students Res. 2015;5(2):28-34. Available from: https: //dx.doi.org/10.4103/ijsr.int_j_stud_res_4_17.

9. Jagadesan S, Harish R, Miranda P, Unnikrishnan R, Anjana RM, Mohan V. Prevalence of overweight and obesity among school children and adolescents in Chennai. Indian J Pediatrics. 2014;51(7):544-549. Available from: https://dx.doi.org/10. 1007/s13312-014-0444-6.
10. Shah JS, Patel PK, Patel B. Determinants of overweight and obesity among school children in Mehsana District, India. Ann Trop Med Public Health. 2013;6(4):408-412.

11. Rao SN, Gurumurthy GP, Gururajan P, Arumugam SB, Saibabu, Kirthivasan V, et al. Clinical and biochemical parameters in relation to serum leptin levels in South Indian children and adolescents. Indian J Pediatr. 2010;77(5):555559. Available from: https://dx.doi.org/10.1007/s12098-0100061-x.

12. Musaiger AO. Overweight and Obesity in Eastern Mediterranean Region: Prevalence and Possible Causes. J Obesity. 2011;2011:1-17. Available from: https://dx.doi.org/10.1155/ 2011/407237.

13. Croezen S, Visscher TL, Bogt T, Veling NC, L M. HavemanNies A: Skipping breakfast, alcohol consumption and physical inactivity as risk factors for overweight and obesity in adolescents: results of the E-MOVO project. Eur J Clin Nutr. 2009;63:405-412.

14. Arora. Association of breakfast intake with obesity, dietary and physical activity behavior among urban school-aged adolescents in Delhi, India: results of a cross-sectional study. BMC Public Health. 2012;12:881-885. 
15. Goyal RK, Shah VN, Saboo BD, Phatak SR, Shahnn, Gohel MC. Prevalence of overweight and obesity in Indian adolescent school going children: Its relationship with socio- economic status and associated lifestyle factors. J Assoc Physicians India. 2010;58(3):151-58.

16. Kaushik JS. Fast food consumption in children. Indian J Pediatr. 2011;48:97-101. Available from: https://dx.doi.org/ 10.1007/s13312-011-0035-8.

17. Subhash B, Thakre, Sheetal P, Mohane, Suresh M, Ughade SS, et al. Correlates of Overweight and Obesity Among Urban School Going Children of Nagpur City. J Clin Diag Res. 2011;5(8):1593-1600.

Copyright: (C) the author(s), 2020. It is an open-access article distributed under the terms of the Creative Commons Attribution License (CC BY 4.0), which permits authors to retain ownership of the copyright for their content, and allow anyone to download, reuse, reprint, modify, distribute and/or copy the content as long as the original authors and source are cited.

How to cite this article: Choudhary B, Singh N, Bathla A, Chand R. Predictors of Overweight and Obesity among Children in Haldwani, Uttarakhand. Asian J. Clin. Pediatr. Neonatol. 2020; $8(2): 11-15$.

DOI: dx.doi.org/10.47009/ajcpn.2020.8.2.3

Source of Support: Nil, Conflict of Interest: None declared. 